\title{
Examination of a PHEV Bidirectional Charger System for V2G Reactive Power Compensation
}

\author{
Mithat C. Kisacikoglu ${ }^{1}$, Burak Ozpineci ${ }^{2}$, and Leon M. Tolbert ${ }^{1,2}$ \\ ${ }^{1}$ Dept. of Electrical Engineering and Computer Science \\ The University of Tennessee \\ Knoxville, TN 37996-2100 \\ ${ }^{2}$ Power and Energy Systems Group \\ Oak Ridge National Laboratory \\ Oak Ridge, TN 37831
}

\begin{abstract}
Plug-in hybrid electric vehicles (PHEVs) potentially have the capability to fulfill the energy storage needs of the electric grid by supplying ancillary services such as reactive power compensation, voltage regulation, and peak shaving. However, in order to allow bidirectional power transfer, the PHEV battery charger should be designed to manage such capability. While many different battery chargers have been available since the inception of the first electric vehicles (EVs), on-board, conductive chargers with bidirectional power transfer capability have recently drawn attention due to their inherent advantages in charging accessibility, ease of use, and efficiency. In this paper, a reactive power compensation case study using just the inverter dc-link capacitor is evaluated when a PHEV battery is under charging operation. Finally, the impact of providing these services on the batteries is also explained.
\end{abstract}

Keywords - PHEV; charger; V2G; reactive power; battery

\section{INTRODUCTION}

Today, hybrid electric vehicles (HEVs) offer customers a way to increase gasoline mileage by having batteries and electric drive systems assist the internal combustion engine. However, HEVs lack the availability to go for more than just short distances at low speeds with only electric power because the battery is not capable of storing enough energy to power the vehicle for a daily commute. PHEVs provide electricityonly drive option up to a specified distance, and they can help reduce carbon emissions as well as other pollutants [1].

While PHEVs will provide economic and environmental benefits, they can also offer a potential source of energy storage which is valuable to the electric power grid. The possibility of using battery-powered vehicles to support the electric grid has been studied for more than a decade [2]. Recent papers including [3-5] have discussed several topologies and control methods that can perform bidirectional power transfer using a PHEV as a distributed energy resource. However, there has not been much technical analysis about reactive power compensation using bidirectional PHEV chargers as well as the effects of such a power support on the PHEV's battery and charger system components.

The purpose of this study is to examine a PHEV charger system to utilize it for reactive power support to the grid. The authors investigate different scenarios to deliver the stored energy from vehicle to grid (V2G) and explain the effects of this usage on the vehicle traction battery and the charger dc link capacitor. In the following section, authors discuss battery charger types briefly. Later, an analysis introduces the dynamics that govern bidirectional power flow in the system and shows how to control the on-board vehicle charger to provide reactive power to the electric grid. The battery of a PHEV can be used for ancillary services such as peak power shaving and reactive power support. However, in the simulation section of this paper, it is observed that compared to peak power shaving, reactive power regulation causes no degradation at all on battery life, since the dc link capacitor is enough for supplying full reactive power for level 1 charging and therefore the PHEV battery is not engaged in reactive power transfer.

\section{ElECTRIC VEHICLE CHARGERS}

Battery chargers play an important role by maintaining the condition and health of the battery while utilizing it for the best performance. A battery charger is a device that is composed of one or more power electronics circuits used to convert ac electrical energy into dc with an appropriate voltage level so as to charge a battery. It has the potential to increase charging availability of the PHEV since it can operate as a universal converter accepting different voltage and power levels. In addition, a battery charger should prevent overcharging from happening. Especially for lithium-ion batteries, the charger warrants a sophisticated charging control algorithm to avoid overcharging [6]. Also, balancing the battery cells requires special circuitry. Consequently, the charger should protect the battery from over-current, overvoltage, under-voltage, and over-temperature [7].

A PHEV battery can be charged either by a separate charging circuit or via using the traction drive that serves to power the electric motor. The first EVs used the former method. Since this option requires an extra charging circuit, it increases the total cost of the vehicle (if the charger is on the vehicle) or it requires a dedicated charging station (if the charger is off the vehicle). If the charger is on-board, it can be optimized to accept different charging levels as well as to match different vehicle battery requirements. With an onboard charger, a vehicle can be charged at any outlet that is available at home garages or workplaces with ground protection [8]. Availability of such charging places will increase the acceptance of PHEV technology. 
On the other hand, off-board chargers make use of fast charging and can charge a vehicle in a considerably shorter amount of time. It is possible to charge a battery in 10 minutes to increase its state of charge (SOC) by $50 \%$ with an off-board charger rated at $240 \mathrm{~kW}$ [9]. Also, according to Nissan, its Leaf electric car, which will be on the road in 2010 and mass produced in 2012, can be charged up to $80 \%$ SOC of its 24 $\mathrm{kWh}$ Li-ion battery pack in around $30 \mathrm{~min}$ at a quick charge station [10].

Since on-board chargers' power rating is limited due to space and weight restrictions on the vehicle, it takes much more time to fully charge a vehicle battery compared to offboard chargers. However, an integrated on-board charger utilizing the traction inverter can charge the battery at high power levels that reduce the charging time [11]. Using these types of chargers which are classified as Level $2+$ chargers, it takes about one hour to put $80 \%$ SOC to a battery rated at 30 $\mathrm{kWh}$ [12]. Not only do integrated chargers connect the vehicle's battery to most available standard $120 \mathrm{~V}$ and $240 \mathrm{~V}$ outlets, with special configuration it also couples a PHEV to an off-board charger if faster charging is needed [11]. However, since integrated chargers use motor inductance as inverter input inductance by connecting the neutral point of the motor to the grid, the inductance of the motor may not be the optimal value for the inverter operation. Also, this design causes the majority of the losses to be the copper losses of the motor windings [5].

An additional point a charger can offer is the capability of transferring power not only from grid to vehicle but also from vehicle to grid so that each car would operate as a distributed power source.

In summary, on-board, conductive chargers with bidirectional power transferring capability have recently drawn attention due to their inherent advantages in cost, charging accessibility, ease of use and efficiency. The following section will present the theoretical analysis of an onboard, conductive charger to utilize it in bidirectional power transfer.

\section{THEORETICAL SYSTEM ANALYSIS OF BIDIRECTIONAL POWER TRANSFER BETWEEN A PHEV AND THE GRID}

\section{A. Grid-Inverter}

The PHEV charger that is analyzed in this study is composed of a full-bridge inverter/rectifier and a dc-dc converter. The analysis will start by investigating the interaction between the grid and the inverter. In order to understand all the dynamics, the basic ideal case is introduced with several assumptions that will make the computation much easier. During the analysis, the positive current direction will be assumed to be from grid to the inverter as shown in Fig. 1. Therefore, positive power sign $(\mathrm{P}=$ active power and $\mathrm{Q}=$ reactive power) corresponds to the power flow from grid to the inverter. The system parameters are given as follows:

\footnotetext{
$v_{c}(t) \quad$ instantaneous charger voltage [V],

$v_{s}(t) \quad$ instantaneous grid voltage [V],
}

$$
\begin{array}{ll}
i_{c}(t) & \text { instantaneous charger current }[\mathrm{A}], \\
L_{c} & \text { coupling inductor }[\mathrm{H}], \\
\delta & \text { phase difference between } v_{c}(t) \text { and } v_{s}(t), \\
\theta & \text { phase difference between } i_{c}(t) \text { and } v_{s}(t)
\end{array}
$$

Root mean square (rms) values of the instantaneous variables are given in capital cases throughout this study.

The grid voltage is assumed to be purely sinusoidal, and high frequency components of inverter output voltage, $v_{c}(t)$, is neglected for analysis purposes as shown by the following equations:

$$
\begin{aligned}
& v_{s}(t)=\sqrt{2} V_{s} \sin (w t), \\
& v_{c}(t)=\sqrt{2} V_{c} \sin (w t-\delta) .
\end{aligned}
$$

In order to ensure power transfer from charger to the utility, a coupling inductor is used and the two voltage sources are decoupled. From Fig. 1 and applying necessary mathematical transformations, the line current can be written as,

$$
i_{c}(t)=\sqrt{2} I_{c} \sin (w t-\theta) .
$$

Since the default direction for active and reactive power transfer is from grid to charger, $i_{c}(t)$ and $v_{c}(t)$ are lagging the grid voltage. Also, note that the reactance is equal to

$$
X_{c}=2 \pi f L_{c},
$$

where the system frequency, $f$, is $60 \mathrm{~Hz}$.

Table I and the P-Q plane shown in Fig. 2 show all the different operation modes in which the system can be working. In order to conserve the amount of energy that is drawn from the battery and to keep the battery undisturbed as much as possible, operation in quadrants I and IV is preferred over working in quadrants II and III. In other words, PHEV battery will not provide active power to the grid in this study. Although the utility may prefer to be able to use the PHEV as a peak shaving power source, it may not be accepted by the vehicle manufacturers and the customers due to safety concerns, decrease in battery lifetime, and reduced available battery energy. The topology that is studied here can run in all four quadrants, but for the analysis the system dynamics will be when the charger is operating in quadrants I and IV.

From Fig. 1 it can also be written that

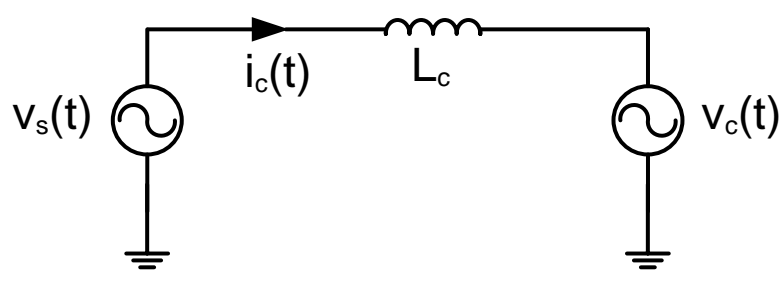

Fig. 1. Representation of grid and charger. 
TABLE I. CHARgER OPERATION MODES

\begin{tabular}{|l|l|l|l|}
\hline$\#$ & \multicolumn{1}{|c|}{ P } & \multicolumn{1}{c|}{ Q } & \multicolumn{1}{c|}{ Operation Mode of the Charger } \\
\hline 1 & Zero & Positive & Inductive \\
\hline 2 & Zero & Negative & Capacitive \\
\hline 3 & Positive & Zero & Charging \\
\hline 4 & Negative & Zero & Discharging \\
\hline 5 & Positive & Positive & Charging and inductive \\
\hline 6 & Positive & Negative & Charging and capacitive \\
\hline 7 & Negative & Positive & Discharging and inductive \\
\hline 8 & Negative & Negative & Discharging and capacitive \\
\hline
\end{tabular}

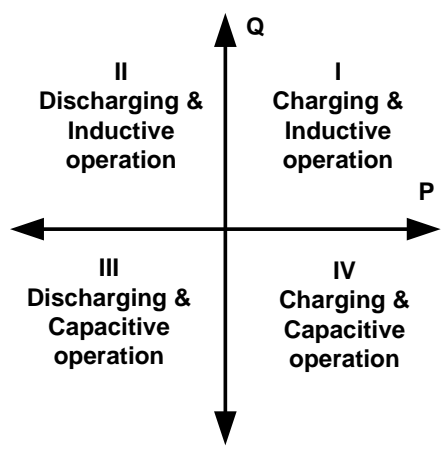

Fig. 2. P-Q plane showing charger operation modes

$$
V_{s}=V_{c}+j X_{c} I_{c}
$$

Using (5), the system variables are shown in the phasor diagrams in Fig. 3 to illustrate the differences between the operation modes. Only the operation modes under discussion are explained in the phasor analysis. Some conclusions drawn from the sketches will help to understand the control algorithm. First, as illustrated in Fig. 3a and Fig. 3b, active power is provided by the grid as long as $v_{c}(t)$ lags $v_{s}(t)$, and it is sent to grid when $v_{s}(t)$ lags $v_{c}(t)$. Since $v_{c}(t)$ and $v_{s}(t)$ are sinusoidal, $i_{c}(t)$ is also sinusoidal as shown before. Its phase angle, $\theta$, determines the direction of the reactive power flow. If $\theta$ is positive, reactive power is sent to the grid, and if $\theta$ is negative, reactive power is provided by the grid to the charger.

Based on the available charging infrastructure, the system will either be charged by level 1 or level 2 charging. Level 3 charging is not examined here. This analysis will be included in a future study. Therefore, the inverter current, $i_{c}$, is limited by the charging equipment to $12 \mathrm{~A}$ or $32 \mathrm{~A}$. For all operations the control algorithm should maintain that the current stays below either of these levels. In Table II, different charging methods in North America are given for further reference.

There are two control methods to influence the magnitude and the direction of $\mathrm{P}$ and $\mathrm{Q}$. The first option is to control the charger voltage, $v_{c}(t)$, and its phase angle, $\delta$. The second option is to control the charger current, $i_{c}(t)$ and its phase angle, $\theta$.

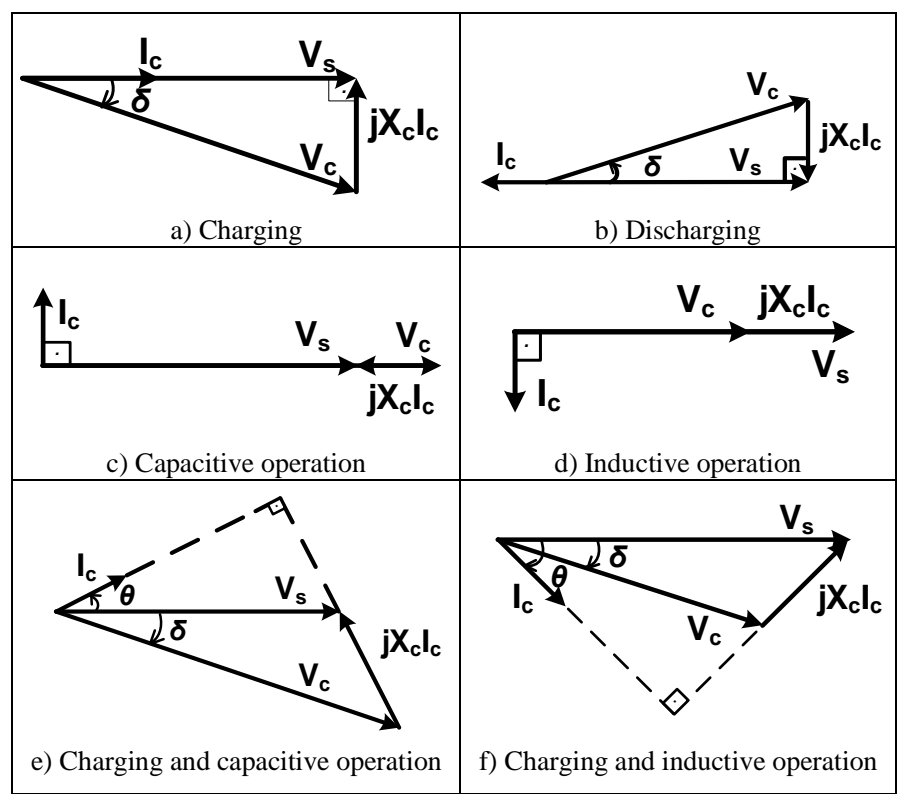

Fig. 3. Vector diagram for different operation modes.

The fundamental equations derived using these variables that govern average active and reactive power flow from grid to inverter is listed in Table III.

In summary, the variables that govern the interaction between the grid and the charger have been introduced in this section. The following section will describe the inverter operation.

\section{B. Inverter}

For this study, a full-bridge PWM inverter/rectifier is used as the first stage of the PHEV charger as shown in Fig. 4. Since the PHEV charger is operating like a current source, it is important that it complies with IEEE 1547 to present the minimum current harmonics possible. Therefore, a hysteresisband current control PWM is used to effectively regulate the current waveform. As a result, current and its phase angle are selected to be the variables of the control algorithm.

The reason for using this topology is to have a system that is able to operate in all four quadrants of the P-Q plane. Although a half bridge inverter could also satisfy this

TABLE II. ElECTRICAL RATINGS OF DifFERENT CHARGING METHODS IN NORTH AMERICA [13]

\begin{tabular}{|l|l|l|l|l|}
\hline $\begin{array}{l}\text { Charging } \\
\text { method }\end{array}$ & $\begin{array}{l}\text { Nominal supply } \\
\text { voltage }\end{array}$ & $\begin{array}{l}\text { Maximum } \\
\text { current }\end{array}$ & $\begin{array}{l}\text { Branch } \\
\text { circuit } \\
\text { breaker } \\
\text { rating }\end{array}$ & $\begin{array}{l}\text { Continuous } \\
\text { input } \\
\text { power }\end{array}$ \\
\hline AC Level 1 & $120 \mathrm{~V}, 1$-phase & $12 \mathrm{~A}$ & $15 \mathrm{~A}$ & $1.44 \mathrm{~kW}$ \\
\hline AC Level 2 & $\begin{array}{l}208 \text { to } 240 \mathrm{~V}, 1- \\
\text { phase }\end{array}$ & $32 \mathrm{~A}$ & $40 \mathrm{~A}$ & $\begin{array}{l}6.66 \text { to } 7.68 \\
\mathrm{~kW}\end{array}$ \\
\hline AC Level 3 & $\begin{array}{l}208 \text { to } 600 \mathrm{~V}, 3- \\
\text { phase }\end{array}$ & $400 \mathrm{~A}$ & As required & $>7.68 \mathrm{~kW}$ \\
\hline DC charging & $600 \mathrm{~V}$ maximum & $400 \mathrm{~A}$ & As required & $<240 \mathrm{~kW}$ \\
\hline
\end{tabular}


TABLE III. FUNDAMENTAL EQUATIONS FOR ACTIVE AND REACTIVE POWER

\begin{tabular}{|l|l|l|}
\hline \multicolumn{1}{|c|}{ Control Variable } & \multicolumn{1}{c|}{$\mathbf{P}$} & \multicolumn{1}{c|}{$\mathbf{Q}$} \\
\hline$v_{c}(t)$ and $\delta$ & $\frac{V_{s} \times V_{c}}{X_{c}} \sin (\delta)$ & $\frac{V_{s}^{2}}{X_{c}}\left[1-\frac{V_{c}}{V_{s}} \cos (\delta)\right]$ \\
\hline$i_{c}(t)$ and $\theta$ & $V_{s} \times I_{c} \times \cos (\theta)$ & $V_{s} \times I_{c} \times \sin (\theta)$ \\
\hline
\end{tabular}

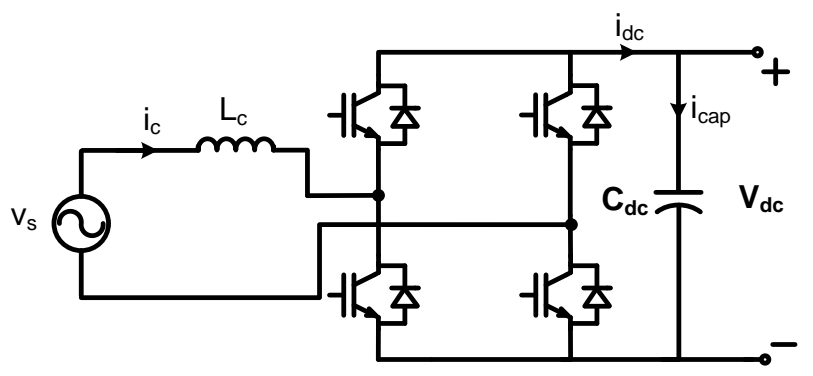

Fig. 4. Full bridge inverter charger.

operation, it requires two large capacitors to effectively regulate their junction voltage. Also, using full bridge active rectifier, the dc link voltage is doubled reducing the output current rating for the same power level.

According to the hysteresis-band current control PWM, the reference current generated by the controller is compared to the actual line current, and the switch pairs change their position accordingly.

The inverter control system shown in Fig. 5 operates with two feedback loops, one is for reactive power regulation and the other is for dc voltage regulation which indirectly facilitates active power transfer to the dc-dc converter. Based on these two feedbacks, the controller calculates the exact $I_{c}$ and $\theta$ values to generate $i_{c}(t)^{*}$ as a reference waveform to be compared with actual line current.

The maximum switching frequency that is shown using hysteresis-band current control PWM is calculated as [14]

$$
f_{\max }=\frac{V_{d c}}{2 L_{c} H} .
$$

where $\mathrm{H}$ is the difference between upper and lower hysteresis bands and equal to $1 \mathrm{~A}$. $L_{c}$ is chosen to be $5 \mathrm{mH}$ and $V_{d c}$ to be $500 \mathrm{~V}$. Therefore, the maximum switching frequency is calculated as

$$
f_{\max }=\frac{500}{2 \cdot 5 \cdot 10^{-3} \cdot 1}=50 \mathrm{kHz}
$$

\section{Dc Bus Components}

In this section, the relationship between reactive power transfer and dc bus variables will be given. The dc parameters that will be analyzed are as follows:

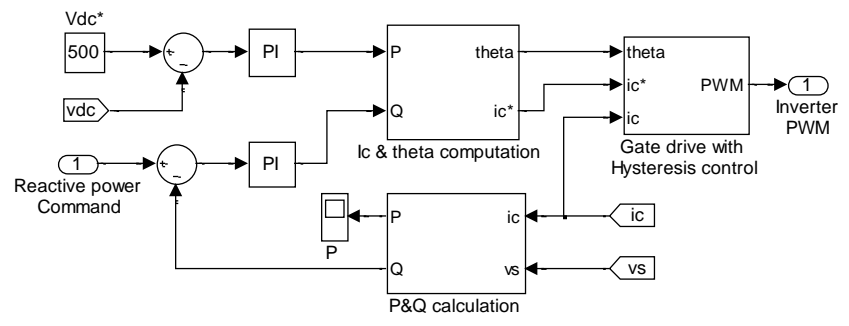

Fig. 5. Control system structure of the inverter.

$V_{d c} \quad$ nominal dc link voltage [V],

$\Delta V_{d c} \quad$ rms dc ripple voltage [V],

$\Delta I_{\text {cap }} \quad$ rms dc capacitor ripple current [A],

$C_{d c} \quad$ dc link capacitor $[\mathrm{F}]$.

The dc link capacitor's major purpose is to regulate dc voltage during battery charging. However, it can also be used for reactive power regulation. First analysis shows how the reactive power transfer affects $\Delta V_{d c}$. As it is given in [15], in a full bridge inverter, the dc link voltage and current exhibit a ripple at double the frequency of the line voltage with the same phase of the line current. For the start of the analysis, the PWM ripples are neglected and only $2 f$ ripple is considered. Therefore, the instantaneous capacitor voltage and current can be defined as

$$
\begin{aligned}
& v_{d c}(t)=V_{d c}+\sqrt{2} \Delta V_{d c} \sin (2 w t+\theta), \\
& i_{c a p}(t)=2 \sqrt{2} C w \Delta V_{d c} \cos (2 w t+\theta) .
\end{aligned}
$$

Dc capacitor minimum and maximum voltages occur at the following time instants:

$$
\begin{aligned}
& 2 w t+\theta=\frac{-\pi}{2} \Rightarrow w t_{\min }=\frac{-\pi}{4}-\frac{\theta}{2} \text { and } \\
& 2 w t+\theta=\frac{\pi}{2} \Rightarrow w t_{\max }=\frac{\pi}{4}-\frac{\theta}{2}
\end{aligned}
$$

In [16], the energy conservation principle is used assuming there is no energy loss. Similarly, it can be written that

$$
\begin{aligned}
& \int_{w t_{\min }}^{w t_{\max }} v_{c}(t) i_{c}(t) d w t=\int_{w t_{\min }}^{w t_{\max }} v_{d c}(t) i_{c a p}(t) d w t, \\
& V_{c} I_{c}\left(\cos (\delta-\theta) \frac{\pi}{2}-\cos (\delta+2 \theta)\right)=2 \sqrt{2} w C V_{d c} \Delta V_{d c} .
\end{aligned}
$$

In addition to this, the net reactive power that is sent to the charger is written as 


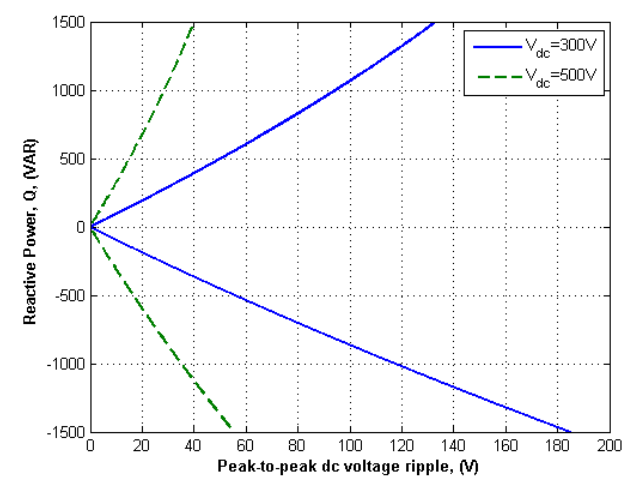

Fig. 6. Peak-to peak voltage ripple for different reactive power levels for a $500 \mu \mathrm{F}$ dc capacitor.

$$
Q=V_{c} I_{c} \sin (\theta-\delta)+w L_{c} I_{c}^{2} .
$$

Using (13) and (14), the relation between reactive power and the peak-to-peak dc voltage ripple can be found as shown in Fig. 6 . The reactive power produced is not directly related to the $V_{d c}$. However, the higher the dc voltage, the lesser the capacitor ripple current. Therefore, the system will be able to supply/sink more reactive power with higher $V_{d c}$ for the same $\Delta I_{\text {cap }}$ levels. Similarly, the dc capacitor value does not affect the reactive power transfer. Rather, $\Delta V_{d c}$ reduces with increasing capacitor rating because the right hand side of (13) should stay constant. Moreover, in the simulation analysis section, the relation observed between reactive power and $\mathrm{dc}$ capacitor rms ripple current will be given.

\section{Dc-dc Converter and Battery}

When charging from the grid, a bidirectional dc-dc converter shown in Fig. 7 steps down the high dc-link voltage and charges the battery using constant current-constant voltage (CC-CV) charging algorithm.

A Li-ion battery model is implemented in Simulink using the model and parameters given in [17-19] to account for the charging profile of a PHEV. The equivalent circuit of a Li-ion battery cell is given in Fig. 8. The nonlinear relationship between open circuit voltage, $V_{o c}$, and SOC is captured using a controlled voltage source. Two RC time constants are used to mimic response to transient power. In Fig. 8, the series resistor, $R_{\text {Series }}$, accounts for the instantaneous voltage drop during a step change in the battery current. Also, $R_{\text {Transient_ } S}$, $C_{\text {Transient_S} S}, R_{\text {Transient_L}}$, and $C_{\text {Transient_L } L}$ stand for short and long time constants that mimic the step response of the battery voltage [17].

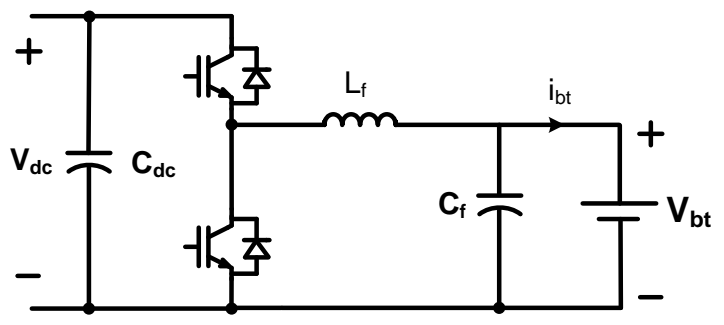

Fig. 7. Dc-dc converter and PHEV battery.

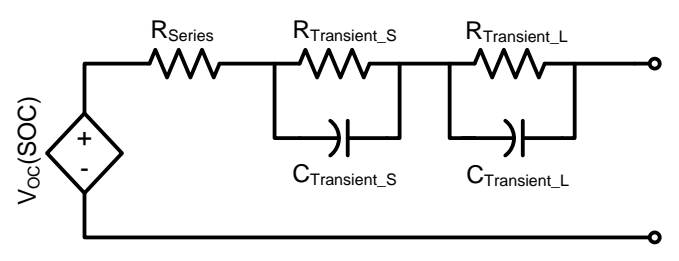

Fig. 8. Electric equivalent circuit of a Li-ion battery cell [17].

In PHEV applications, the required amount of terminal voltage and capacity of the energy storage system is obtained arranging multiple battery cells in series and parallel. The cells that are in series determine the terminal voltage of the battery system, and the number of parallel cells decides the current carrying capability of the system. The total capacity of the battery is given as

$$
C_{t}=C_{i} n_{s} n_{p}
$$

where $C_{t}$ is the total capacity (Ah); $C_{i}$ is the cell capacity (Ah); $n_{s}$ is the number of cells in series; and $n_{p}$ is the number of cells in parallel. As given in [17], the capacity of individual cells, $C_{i}$, modeled is $0.85 \mathrm{Ah}$. The Li-ion battery cell model is scaled up to $5 \mathrm{kWh}$ to account for the battery size as it is used in Toyota Prius Hymotion PHEV [20]. If each cell is assumed to be operating at $3.8 \mathrm{~V}$, then 53 cells in series and 29 cells in parallel constitutes this capacity as shown below:

$$
E=C_{i} n_{s} n_{p} V_{t}=0.85 \cdot 53 \cdot 29 \cdot 3.8 \approx 5 \mathrm{kWh} .
$$

where $V_{t}$ is the nominal terminal voltage of each cell $(\mathrm{V})$. The implemented battery model output signal is generated in a Simulink model and then transferred to a PLECS software block which is embedded in Simulink for power processing stage.

\section{E. Reactive Power Support During PHEV Charging}

In this section, the potential for reactive power regulation during battery charging is explored using the experimental measurements of the charging power drawn by the 2008 Toyota Prius PHEV [20]. For this purpose, the battery pack of the Toyota Prius has been depleted and recharged several times, and the resulting waveforms are given in Fig. 9.

In Fig. 9, P1, P2, and P3 stand for three different level 1 charging profiles observed when charging the PHEV. When it is first plugged in, the battery voltage level is at its minimum, and there is an excess current margin that can be utilized for reactive power generation for about 45 minutes. During this time, the battery is charged with constant current, and its terminal voltage increases gradually; the line current increases gradually too. The amount of reactive power that the system can supply until the charger reaches its maximum power is calculated by the following formula:

$$
|Q|=\sqrt{\left|V_{s} \times I_{c}\right|^{2}-|P|^{2}} .
$$




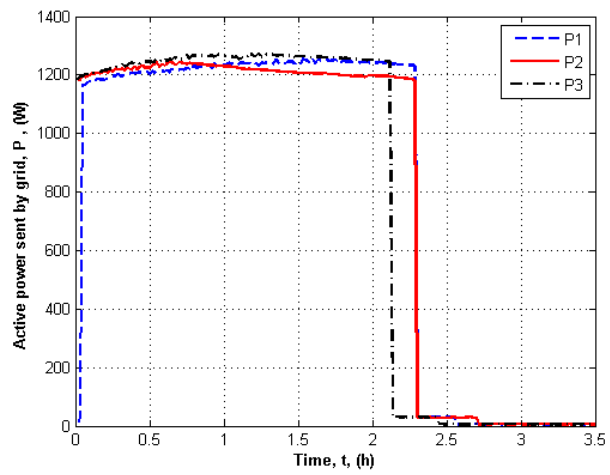

Fig. 9. Experimental data for the charging power of Toyota Prius PHEV converted by Hymotion.

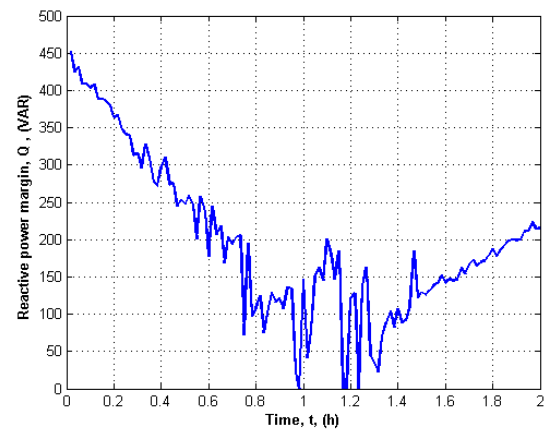

Fig. 10. Reactive power availability during constant current charging of the Toyota Prius PHEV.

Using (17), the available reactive power is given in Fig. 10 for charge profile P3. For this data, the maximum power drawn from the grid is $1.27 \mathrm{~kW}$ with almost 1.0 power factor. For the reactive power calculation, the apparent power is limited to be $1.27 \mathrm{kVA}$ to limit the peak current.

As illustrated in Fig. 10, even during constant charging, there is an opportunity to supply $0.45 \mathrm{kVAR}$ power to grid which is still $35 \%$ of the full reactive power amount that can be supplied without charging the battery.

\section{Simulation ANALYsis}

The purpose of the simulation study is to verify that the proposed system is able to work in the aforementioned operation modes. Also, the effect of different operation modes on the dc variables will be given. The system will be commanded to work in two quadrants although the topology is able to work in all four quadrants. Moreover, the system is compatible to work with both level 1 and level 2 charging equipment. However, since everything except the ratings will stay the same for the analysis, only level 1 will be evaluated. All the results have been achieved using a $500 \mu \mathrm{F}$ dc capacitor and $500 \mathrm{~V}$ dc voltage level.

Because of the long simulation time, the system is only simulated for a few seconds. A safety limit is imposed on the line current not to exceed the system limitations at all operation modes.

The simulation realizes the operation modes \#1, \#2, \#3, \#5 and \#6 as given in Table I respectfully in 11 s. In Fig. 11, the

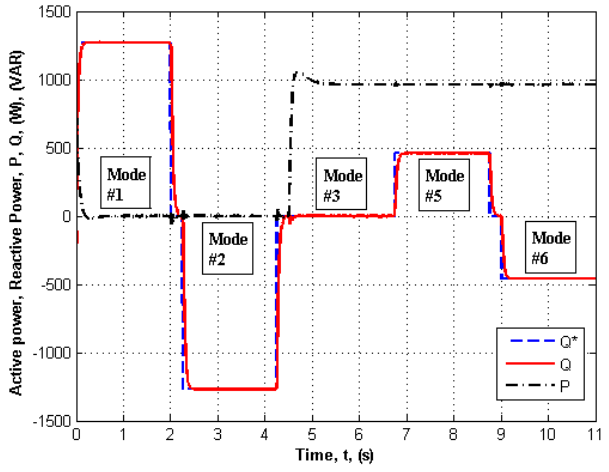

Fig. 11. Reactive power demanded by the controller and supplied by the charger.

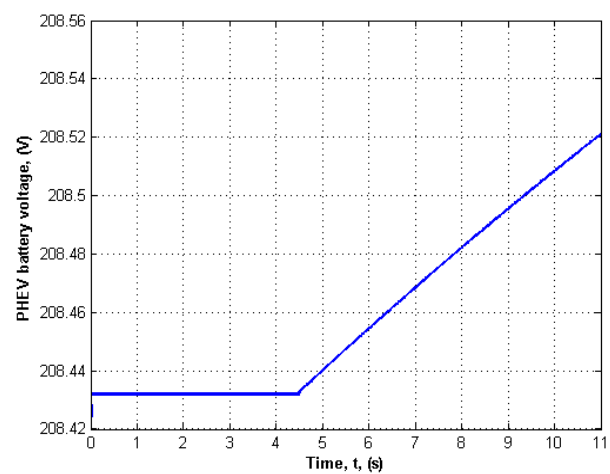

Fig. 12. PHEV battery terminal voltage.

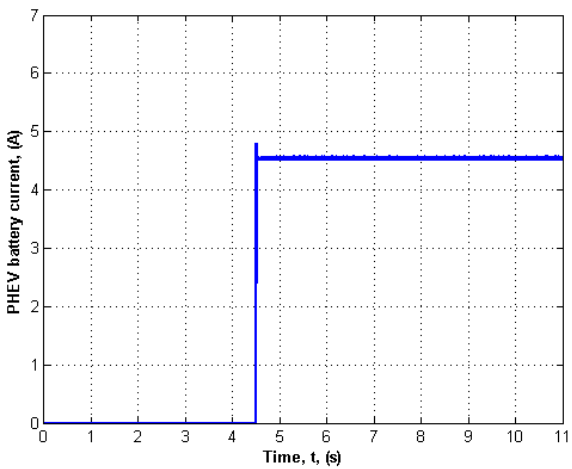

Fig. 13. PHEV battery terminal current.

reactive power command to the charger is given along with the charger's response as $\mathrm{Q}^{*}$ and $\mathrm{Q}$ respectively. Also, in the same graph, the active power sent by the grid to charge the PHEV battery is included. Since it takes considerable amount of time to cover all the charging process of the battery, only the initial part of the constant current charging is shown. Finally, towards the end of the simulation, the bidirectional charger provides reactive power in response to the controller command when the PHEV is plugged in for charging operation. Note that, minus sign stands for capacitive operation and positive sign means inductive operation.

Following Fig. 11, in order to show that the PHEV battery is not used to supply reactive power regulation during the simulation, battery terminal voltage and current are given in Figs. 12 and 13, respectively. During the simulation, battery voltage and current have not shown any deviance from their 
usual profile satisfying safe operation regulations. In other words, the battery is always operated such that the current and voltage ripple presented are the same as it is during a normal charging operation.

After confirming that the designed system is able to operate at the planned operation modes without putting adverse effects on the battery, the effects of the different operation modes on the dc bus variables should be presented to investigate if the $\mathrm{dc}$ dynamics of the system pose a danger on the dc link capacitor.

First, the dc link capacitor voltage has shown a profile with a frequency that is double the line frequency as expected. Fig. 14 shows the regulation of dc voltage during the simulation. When the PHEV is plugged in to be charged at $4.5 \mathrm{~s}$, the dc link voltage suddenly drops and then regulates itself.

Fig. 15 shows the changes in the dc capacitor peak to peak ripple voltage when the system operates at different modes. For reactive power only operation, the dc link capacitor is exposed to $\sim 13 \mathrm{~V}$ peak-to-peak voltage ripple when absorbing $1.27 \mathrm{kVAR}$ from grid (mode \#1) and $\sim 18 \mathrm{~V}$ when supplying $1.27 \mathrm{kVAR}$ to grid (mode \#2). Because of the coupling inductor, it requires less voltage ripple to absorb reactive power. These results confirm well with the initial analysis equations, (8) - (13) and Fig. 6. If the PHEV is used to sink reactive power from the grid during charging (mode \#5), it only requires $\sim 1 \mathrm{~V}$ more peak-to-peak ripple voltage and around $\sim 2 \mathrm{~V}$ more for capacitive operation (mode \#6).

Fig. 16 also illustrates how the capacitor ripple current changes with different operation modes. The net change in the rms ripple current is small when the charger switched between different operation modes keeping the dc link capacitor in its safe operating limits.

The results confirm that, with level 1 charging, supplying ancillary services such as reactive power compensation can be achieved with an on-board, conductive, and bidirectional charger without using the PHEV battery and keeping the dc link capacitor in its operating limits.

\section{CONCLUSION}

The basis of this paper is to introduce the technical understanding of the $\mathrm{V} 2 \mathrm{G}$ reactive power compensation. Therefore, V2G operation is shown by simulating different modes of operation out of which reactive power supply/sink with/without PHEV battery charging being the most important ones.

The simulation study showed that with level 1 charging, it is possible to fulfill reactive power compensation without any power demand from the battery. Moreover, the dc link capacitor of the bidirectional charger is used to supply reactive power. The results show that reactive power compensation can be accomplished with/without battery charging and it does not put stress on the dc link capacitor. The peak to peak ripple of the dc voltage and dc capacitor rms ripple current are observed for safety of the dc link capacitor.

Future study will be on engaging the PHEV battery for the reactive power support at higher power levels and showing if there are adverse effects of this operation on the battery.

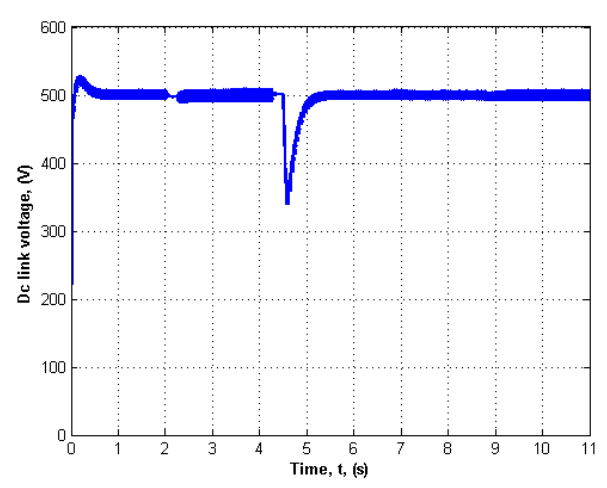

Fig. 14. Dc link voltage when charging PHEV battery.

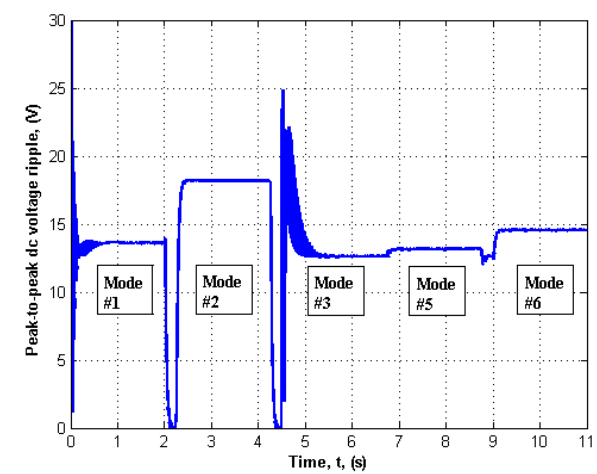

Fig. 15. Peak-to-peak ripple voltage seen on the dc link capacitor for different operation modes (\#1,2,3,5, and 6 in Table I).

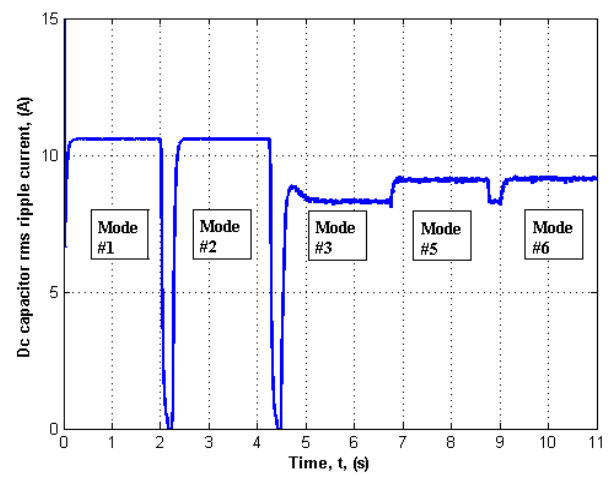

Fig. 16. Rms de link capacitor current for different operation modes (\#1,2,3,5, and 6 in Table I).

\section{REFERENCES}

[1] Electricity advisory committee, "Bottling electricity: storage as a strategic tool for managing variability and capacity concerns in the modern grid," December 2008.

[2] W. Kempton, and A. E. Letendre, "Electric vehicles as a new source for electric utilities," Transport. Res. Part D Transport. Envir., vol. 2, no 3, pp. 157-175, September 1997.

[3] X. Zhou, et. al., "Design and control of grid-connected converter in bidirectional battery charger for plug-in hybrid electric vehicle application," Vehicle Power and Propulsion Conference (VPPC'09), Dearborn, MI, USA, 7-10 September 2009.

[4] I. Cvetkovic, et. al. "Future home uninterruptable renewable energy system with vehicle-to-grid technology," Energy Conversion Congress \& Exposition (ECCE'09), San Jose, CA, USA, September 20-24, 2009. 
[5] L. Tang and G.-J. Su, "A low-cost, digitally-controlled charger for plugin hybrid electric vehicles," Energy Conversion Congress \& Exposition (ECCE'09), San Jose, CA, USA, September 20-24, 2009.

[6] J. Voelcker, "Lithium batteries take to the road," IEEE Spectrum, pp. 27-31, September 2007.

[7] M. F. M. Elias, et. al. "Lithium-ion battery charger for high energy application," National Power and Energy Conference, 15-16 December 2003.

[8] P. V. D. Bossche, " The electric vehicle: raising the standards," Ph.D. dissertation, Vrije Universteit Brussel, 2003.

[9] California Air Resources Board, "Staff Report: Initial Statements of Reasons - Proposed Amendments to the California Zero Emission Vehicle Regulations: Treatment of Majority Owned Small or Intermediate Volume Manufacturers and Standardization of Battery Electric Vehicle Charging Systems for the Zero Emission Vehicle Program," May 2001.

[10] Nissan Leaf Electric Car, http://www.nissanusa.com/leaf-electric-car.

[11] Reductive charging, Available online: http://www.acpropulsion.com.

[12] W. Korthof, "Level 2+: Economical Fast Charging for EVs," 17th Electric Vehicle Symposium, Montreal, Canada, October 2000.

[13] SAE J1772 Electric vehicle conductive charge coupler and SAE J1773 Electric vehicle inductively coupled charging, Society for Automotive Engineers, Inc.
[14] L. J. Borle, "Zero average current error control methods for bidirectional ac-dc converters," Ph.D. dissertation, Curtin University of Technology, October 1999.

[15] N. Mohan, T. M. Undeland, and W. P. Robbins, "Power Electronics converters, applications and design," $3^{\text {rd }}$ ed. John Wiley \& Sons, Inc., 2003, pp. 214-215.

[16] Y. Xu, "A generalized instantaneous nonactive power theory for parallel nonactive power compensation," Ph.D. dissertation, Elec. and Comp. Eng. Dep., University of Tennessee, 2006.

[17] M. Chen and G. A. Rincon-Mora, "Accurate electrical battery model capable of predicting runtime and $\mathrm{I}-\mathrm{V}$ performance," IEEE Trans. Energy Convers,. vol. 21, no. 2, pp. 504-511, June 2006.

[18] M. Knauff, et. al, "Simulink model of a lithium-ion battery for the hybrid power system testbed," Proceedings of the ASNE Itelligent Ships Symposium, Philadelphia, PA, USA, May 2007.

[19] Erdinc, O., Vural, B., and Uzunoglu, M. "A dynamic lithium-ion battery model considering the effects of temperature and capacity fading," 2009 International Conference on Clean Electric Power, Capri, Italy, 9-11 June 2009.

[20] A123 Systems Hymotion Products http://www.a123systems.com/hymotion/products/N5_range_extender. 